\title{
B Reserach S Surare \\ Under Careful Construction: Combining Findings, Arguments, and Values Into Robust Health Care Coverage Decisions
}

\section{T.H. Kleinhout-Vliek ( $\nabla$ vliek@eshpm.eur.nl )}

Erasmus University Rotterdam

\section{A.A. de Bont}

Erasmus University Rotterdam

\section{A. Boer}

Erasmus University Rotterdam

\section{Research Article}

Keywords: Health Care Decision-making, Health Care Coverage, Expertise, Patient and Public Involvement and Engagement, Robustness

Posted Date: July 1st, 2021

DOI: https://doi.org/10.21203/rs.3.rs-651455/v1

License: (9) This work is licensed under a Creative Commons Attribution 4.0 International License. Read Full License 


\section{Abstract}

Background: Health care coverage decisions deal with health care technology provision or reimbursement on a national level. The coverage decision outcome, i.e., the publicly available document with reasons for the decision, may contain various elements: quantitative calculations like cost and clinical effectiveness analyses and formalised and non-formalised qualitative considerations. We know little about the process of combining these heterogeneous elements into robust decision outcomes.

Methods: In this study, we describe a model for combining different elements into coverage decision outcomes. We build on two qualitative cases of coverage appraisals at the Dutch National Health Care Institute, for which we analysed observations at committee meetings ( $n=2$, with field notes taken) and analysis of audio files ( $n=3)$, interviews with appraisal committee members ( $n=10$ in seven interviews) and with Institute employees ( $n=5$ in three interviews).

Results: We conceptualise decision outcomes as combinations of elements, specifically (quantitative) findings and (qualitative) arguments and values. Our model contains three steps: 1) identifying elements; 2) designing the combinations of elements, which entails articulating links, broadening the scope of designed combinations, and black-boxing links; and 3) testing these combinations and choosing one as the final decision outcome.

Conclusions: The proposed model highlights decision makers' expertise in composing both elements and combinations. It also provides additional rationales for facilitating appeals and engaging patients and the public. Future research efforts could further explore the relationship between robustness and decision combination strength.

\section{Introduction}

Health care coverage decisions outline whether or not a specific health care technology is to be provided or reimbursed on a national level. In many cases, a document with reasons to explain these decisions is made available to the public. Various elements may be present in such a decision document. The (generally quantitative) evidence collated and generated through Health Technology Assessment is but a part of this: many formalised criteria lists also contain qualitative considerations (1-4). Moreover, a growing body of literature establishes the impact of additional, non-formalised or 'contextual' factors on these decisions, with some noting inconsistencies in the use of formalised criteria (5-9). In short, many heterogeneous elements may be present in the decision document. These elements are typically brought together in a deliberative setting.

Since the turn of the century, scholars have closely examined the deliberative processes on health care coverage (10-12), showcasing the interactional work required during deliberation (13). In essence, this interactional work comprises clustering, i.e., establishing coherence between these heterogeneous elements (14-16). These heterogeneous elements would (ideally) be contributed by a diverse set of actors 
and combined into what Science and Technology Studies scholars have previously called a 'robust' decision (17-23).

Many authors working inductively on these deliberations have shown how they involve combining rationales. These authors generally draw conclusions at a relatively broad level, not infrequently classifying deliberations and their outcomes as 'pragmatic' $(18,24-27)$. Russell devised and employed a rhetorical policy analysis method to study deliberations, concluding that decisions are 'practical productions' interwoven with 'big D' policy discourse (28). We owe much to her work on how different quantitative and qualitative elements, criteria and case-specific arguments, are routinely combined into decisions that are both 'rational' and 'human' (24). Russell did, however, not concern herself with distinguishing generalisable steps in clustering the variety of elements into a decision outcome.

In this paper, we construct a model for clustering elements during deliberations on health care coverage, drawing from literature on decision making that yields outcomes that are 'robust', that is, able to withstand pressure in society. Accordingly, we will conceptualise decision outcomes, i.e., the publicly available reasons provided for a decision, as combinations of elements. The element types we distinguish are findings, arguments, and values. We describe three steps to achieving robust decision outcomes: 1) identifying elements, 2) designing combinations of elements, and 3) testing these different combinations. We will illustrate and confront this model with data gathered in qualitative comparative case research on two Dutch health care coverage decisions, namely on maternity care and paracetamolvitamin D tablets. This analysis will lead to several recommendations for policy and research.

Three-step model: robust decisions as combinations of elements

STS scholarship considers controversies fruitful sites for exploring technology's role in society $(29,30)$. Scholars have described how polities have dealt with controversies as diverse as nuclear power plants, radioactive waste storage, Bovine Spongiform Encephalopathy, HIV/AIDS, Genetically Modified Organisms, nanotechnology, and coverage decisions $(17,18,31)$. These studies describe the work put in to uphold or defuse a controversy, highlighting the insufficiency of traditional, 'certified' expertise, always making the reader sensible to the many ways in which controversies come to be and in which closure was perhaps achieved (30).

Rip (20-22) advocates focusing on the production of robustness. Generally, STS scholars define robustness as 'surviving' public pressure or incorporating 'non-certified' expertise $(23,32)$. Rip embarks upon his operationalisation of robust decisions through 'informal technology assessment', in essence, a public litmus test for decision outcomes. According to Rip, robust outcomes can withstand "the pressures to which they will inevitably be exposed" $(19,20)$. According to Rip, these decisions may contain:

"arguments, evidence, social alignments, interests, and cultural values, many of them interrelated and therefore lending support to the dominant view. The difference between an only fashionable and a robust view is a matter of degree, and perhaps also a matter of actual effort that actors are prepared to exert." (21) 
Robust decisions thus contain heterogeneous elements, and actors need to exert substantial effort to identify these elements. Thus, the first step of our model is: identifying potentially relevant elements. Elsewhere, Rip speaks of "findings, arguments, perceptions, interests, and dominant values" (22). We will focus on three of these elements generally present in health care coverage decisions, knowing that this is a reduction of the variety of elements present. These elements are: 1) findings of experts in the shape of Health Technology Assessments and the like; 2) arguments such as what concerns good care; and 3) values such as justice, equality, and solidarity $(3,14,25,33,34)$.

The second step we derive from literature is: designing linked combinations of elements. As Rip continues,

"[Both fashionable and robust views] are available in the cultural repertoire, but with increasing robustness, the linkages between elements of the view and with their context increase in number and in articulation (and sometimes also in scope)." (21)

Rip highlights the availability of different possible combinations of elements, which differ in robustness. Some are on the "fashionable" end of the spectrum, while others are on the more robust end. To achieve a robust view, whoever is arguing needs to link elements into clusters of factors $(15,16)$. We will conceptualise these linked sets of elements as 'combinations'. Setting up robust combinations of elements involves matching up, 'clicking together', these elements (21). In a similar vein, Callon, Lascoumes and Barthe advocate "the design and testing of (...) [multiple] solutions that integrate a plurality of points of view, demands, and expectations" (17, emphasis added). We classify this bringing together of elements into different combinations as designing these combinations.

Rip distinguishes two different linking activities, namely articulation and consolidation. By articulation, he understands that the speaker actively joins previously unlinked elements and that this may also result in an increase in number. In some cases, this may also involve increasing the scope of the decision. Consolidation, for Rip, is the next step in robustness, linking several elements so firmly together that the link itself is 'black-boxed' and becomes difficult to call into question (21). In our model, designing the combination will take three distinct forms: links are actively articulated, they are increased in number and sometimes increased in scope, or the links are black-boxed.

After identifying the elements and designing multiple combinations, our model's third step is to test the combinations of elements. We derive this idea of testing different combinations from Callon et al., who specify testing to entail a series of negotiations and compromises between all present (17). They argue that such confrontation should be part and parcel of the decision-making process instead of remaining 'out there': it is to be actively encouraged in a 'safe' space as more and more different people have a stake and a say. Callon et al. envision this to happen in what they term hybrid forums. In these, specialists and laypersons design and test several combinations of elements together (17). Such learning resonates with Rip's earlier work (21); Nowotny (23) even conceptualises robustness as resulting specifically from such repeated testing. 
In this paper's remnant, we will show how the decision trajectories of two specific cases, namely the Dutch health care coverage decisions on maternity care and paracetamol-vitamin D tablets, illustrate and confront this 3-step model as they link multiple, heterogeneous elements into relatively robust combinations.

Comparative case methodology

This paper builds on research at the Dutch Health Care Institute and employs a case approach $(35,36)$. Case analysis is well-placed to provide insight into health care coverage decisions as it gives an in-depth take on processes that entail valuation $(14,37,38)$. We opted for two cases with high contrast (Lamont \& Thévenot, 2000) regarding decision outcome, the number of patients affected, type of technology, and price: maternity care and paracetamol-vitamin $D$ tablets (for more information, see boxes 1 and 2, with both descriptions previously published in 39). The Dutch media discussed both cases briefly (40, 41). Both cases were 'revisited' decisions; they were already part of the basic benefits basket, but this status was now questioned (9). For this reason, these are cases where decision makers are likely to have constructed the decision carefully.

The data consisted of observations at appraisal committee meetings $(n=2$, both for paracetamol-vitamin D tablets, with field notes taken) and analysis of audio files ( $n=3$, with one for the maternity care case and the other two of the observed meetings), interviews with committee members ( $n=10$ in seven interviews) and with Institute employees ( $\mathrm{n}=5$ in three interviews). The interviews were all semi-structured and 'field formal' $(42,43)$. Moreover, we analysed four documents pertaining to the two decisions. The secretary of the appraisal committee granted access to the meetings and (audio) files. Previous observations at appraisal committee meetings $(n=2)$ enriched the data analysis (see tables 1 and 2 ).

Table 1 - overview of documents and audio files analysed per case

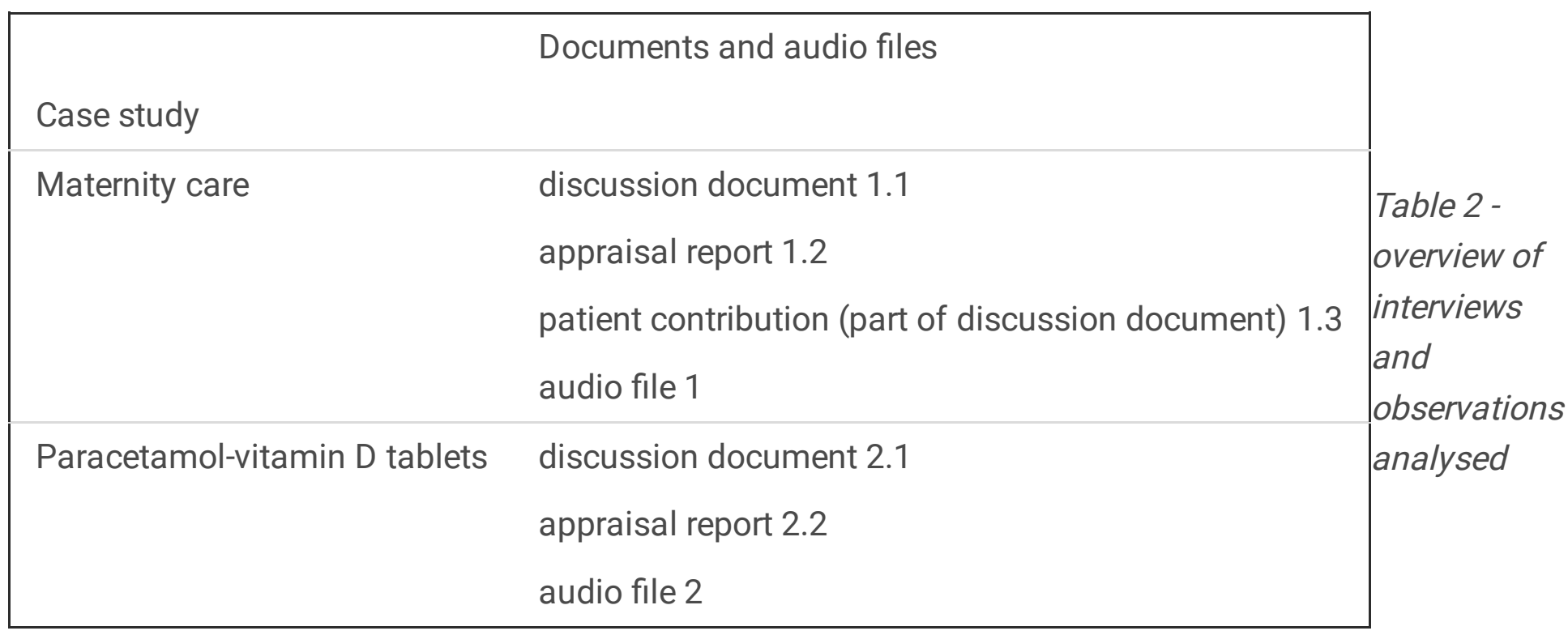




\begin{tabular}{|ll|}
\hline $\begin{array}{l}\text { Interviews and observations } \\
\text { date }\end{array}$ & Description \\
\hline January 2015 & Appraisal committee maternity care audio file only \\
\hline March 2015 & Institute employee 6 \\
\hline March 2015 & Committee member 5 \\
\hline August 2015 & Committee member 3 \\
\hline September 2015 & Committee member 2 \\
\hline November 2015 & $\begin{array}{l}\text { Appraisal committee paracetamol-vitamin D tablets observations and } \\
\text { audio file }\end{array}$ \\
\hline October 2016 & Committee member 5 \\
\hline October 2016 & Institute employees 1 \& 7 \\
\hline October 2016 & Institute employees 2 \& 5 \\
\hline October 2016 & $\begin{array}{l}\text { Appraisal committee paracetamol-vitamin D observations and audio } \\
\text { file }\end{array}$ \\
\hline February 2017 & Committee members 1, 4, 5 \& 6 \\
\hline February 2017 & Committee member 1 \\
\hline October 2017 & Committee member 6 \\
\hline
\end{tabular}

Dutch health care coverage decisions

In the Netherlands, all citizens are insured through private insurance, which covers at least the bare minimum set by the government: the basic benefits basket. The Dutch Health Technology Assessment (HTA) agency, the National Health Care Institute (in Dutch: Zorginstituut Nederland, in the rest of this paper: 'the Institute'), is responsible for advice to the Minister of Health regarding the contents of this benefits basket. The Institute utilises four formalised criteria to come to this advice. These are: 1) effectiveness and 2) cost-effectiveness of the health care technology, 3) feasibility of coverage (including total budget impact), and 4) necessity, which rests in part on the individual severity of illness and individual affordability (44). These well-established criteria (45) are brought together in the final advice document sent to the Minister, who makes the final decision.

The process of coming to this advice comprises several steps, relatively common in its set-up $(46,47)$. Generally, it starts with a scoping session inviting stakeholders to submit initial comments on the health care technology under consideration. The assessment phase follows, wherein the scientific evidence, which includes information on the effectiveness, cost-effectiveness, budget impact, severity of illness, and affordability, prepared by Institute employees, is rigorously examined by the assessment committee (in Dutch: Wetenschappelijke Adviesraad). The appraisal committee subsequently contextualises the outcomes of this examination (in Dutch: Adviescommissie Pakket). In this meeting, which specifically 
aims to 'bring in' broader societal values, the scientific evidence is first presented by an Institute employee, followed by input from patients (representative)s and other stakeholders. Subsequently, the appraisal committee, which comprises eight to ten external experts from fields such as pharmacoeconomics and health care ethics, commences their deliberations. At the end of these deliberations that allow each member to speak and respond, the committee formulates the final advice. This advice is then summarised, approved by the Institute's Board of Directors, and forwarded to the Minister $(48,49)$.

The three-step model in practice

Our conceptual model comprises three steps to be taken in deliberation resulting in robust decisions, which we conceptualise as combinations of heterogeneous elements. The first step is the identification of different elements (findings, arguments, values). Second, combinations of elements are designed by linking elements, broadening the combination's scope, and black-boxing links. In the third and final step, decision makers confront or 'test' the combinations for robustness and choose one combination as the final health care coverage decision.

Step 1: Identifying elements

The first step in coming to a robust decision is identifying different elements that may make up the combination. We are not suggesting that identifying 'all' elements is possible; instead, efforts in this area are rewarded with many different elements and many different types of elements. One way to obtain many elements is by inviting experts-by-experience and laypeople, such as patients or other members of the public, into the deliberative setting of the decision. In the Dutch appraisal committee, deliberations do start with contributions from Institute employee(s) and, sometimes, patient (representative)s. The appraisal actively invites these contributions, treating them as valuable, especially as structuring the deliberations regarding coming to an advised decision $(26,50)$.

Box 1 - maternity care case description

The maternity care case was addressed by the appraisal committee in January 2015 in response to an appeal to the general public by the Minister of Health to send in suggestions for parts of the basic benefit package that could be removed. The primary argumentation for suggesting that maternity care could be removed from the package was that pregnancy is a choice and foreseeable (that is, unnecessary to be insured for, as the birth is something you know will happen). In line with this, mere days before this appraisal committee meeting took place, Trouw, a Dutch newspaper, had commented on how strange it was that "beschuit met muisjes smeren" (the preparation of a traditional Dutch treat for friends and family paying maternity visits) was often done by maternity care workers and therefore part of the basic benefit package. The Institute employees, however, concurrently received "signals" from the Ministry that it should not be removed from the benefits basket (Institute employees 2 and 5, interview). Several versions of the advice document had to be discussed at the appraisal committee, which led to much frustration at coffee machine afterwards. The final document, however, was the first where the criteria 
were used "really well" (interviews with Institute employees 6 and 5). The deliberations in the appraisal meeting focused on two elements. First, "the domain question": to what extent is maternity care a type of curative care? The second element concerned the idea of whether the need for maternity care is "foreseeable", meaning that if you know you are going to need something someday, you should not be insured for it (as you can save up, you know it is coming). The final decision was indeed to continue maternity care coverage.

\section{Box 2 - paracetamol-vitamin D case description}

The paracetamol-vitamin $D$ tablets file came onto the agenda of the Institute due to some national policy changes, by which a fairly large number of tablets was left behind on a list of covered medications (in Dutch: Geneesmiddelenvergoedingssysteem). In a letter to the Institute, the Minister of Health explicitly stressed the need to pay attention to the necessity of coverage of these tablets, which included $1000 \mathrm{mg}$ paracetamol, vitamin $\mathrm{D}$, and calcium tablets. The Institute employees responsible acknowledged that they, at first, called it an "outflow advice", but were "not allowed" to call it that (interview with Institute employees 1 and 7). It was discussed at the appraisal committee in October and November 2016. A number of pharmacists had inputted, as patient representatives, to the scoping session; the secretary of the committee, brought in the argumentations supplied by them. As a consequence, much of the deliberations focused on what constitutes individual affordability for specific vulnerable groups. The second element that was primary in the discussions was the comparator medicines; if we compare it to other medicines available at the drug store without a prescription, it should not be reimbursed. As a corollary, the question was whether these medicines constituted "self-care" medicines or not. The final advised decision was to not cover paracetamol-vitamin $D$ tablets except for certain medical indications. The rationale was that reimbursing would actually be more expensive than not, because of the prescription rule. This rule is an extra charge levied when a reimbursed medicine is bought at the pharmacy on prescription, which was circumvented by the negative advised decision.

These contributions contain the three types of elements we identified: findings, arguments, and values, visible in the dataset on maternity care (see box 1 ) and paracetamol-vitamin $D$ tablets (see box 2; both descriptions previously published in 39). Findings included the individual severity of illness and the financial cost of the paracetamol-vitamin $D$ tablets for the patient if they would not be covered by the benefits basket, contributed by the Institute employee. Arguments include that maternity care workers have an essential signalling function to other health care professionals when there are problems or highrisk situations with the mother and baby, and how upon exclusion from the benefits basket, this would need to be arranged differently. For paracetamol-vitamin D tablets, arguments included the fact they considered substitution to heavier medicines likely, contributed by pharmacists. In both cases, values mentioned by a committee member included solidarity with vulnerable groups such as chronically ill, elderly patients, or new mothers who might not be able to afford maternity care (audio files 1 and 2).

This overview and some of the data below highlight that the provenance of argumentations marshalled by the committee may sometimes be patients or even newspaper articles. Such dynamics raise questions 
on the identity and distinctiveness of expertise and its role in policy-making - not for nothing has this been a long-standing debate in STS and adjacent fields (20,32, 51-55). In terms of both these aspects, we would follow Callon, Lascoumes (17) and Moreira (18), Moreira (19) in not teasing out the quality differences between contributions but holding that more types of contributing people will likely yield more types of elements. Naturally, these elements may clash with one another; some will argue in favour of and others against coverage of this particular health care technology (56). However, such clashing is not problematic as they may become part of different combinations (see step 2 below).

Step 2: Designing combinations

In arriving at a robust decision, the second step is designing the combinations of elements (17). We separate this step into three distinct activities: articulating links between elements, broadening the combination's scope, and black-boxing links (21).

Articulating links is the primary method for connecting elements into decisions (cf. 15, 16). The document with reasons provided for a decision always contains a variety of both formalised criteria and casespecific argumentations $(5,9)$. Links are made all the time in deliberations, and we are specifically interested in links made between different types of elements. The paracetamol-vitamin $D$ case gives an example:

"People who take these medicines often have more costs due to comorbidity and/or cannot afford them because of a low average income coupled to lower socioeconomic status" (Discussion document 2.2).

As this served as argumentation in favour of coverage, this is an explicit linking of the value of equity (people with lower socioeconomic status or other costs should also be able to take these medicines) with the finding of the severity of illness (comorbidity) and the argument of personal responsibility (they should thus not be personally responsible). For the maternity care case, a strongly linked combination was already available before the deliberations started but was explicated during the deliberations because maternity care arrived on the decision agenda of the Institute in an unusual way. In Buitenhof, a well-known political tv programme, the Minister of Health had asked stakeholders and members of the public what forms of care, in their opinion, would not need to be covered by the benefits basket. Maternity care was selected out of 3921 suggestions received by the Minister to be decided on by the Institute. A few newspapers picked this up. The line of argumentation, this linked combination, was formulated by a committee member during the committee deliberations as follows:

"There are signals that solidarity no longer goes without saying. To put it bluntly: "I do not think I shall need maternity care for the rest of my life, so l'm not going to pay for it". [Some commotion from the rest of the committee, committee member 8 is invited to continue]. "Things could be a bit more nuanced. If you look at that article in Trouw [Dutch newspaper] of this week, following the draft advice that was released, you'll see that maternity care is associated straightaway with prepping beschuitjes." [Laughter] "And if at that point someone would say, "Wait a minute, er, should I pay for that?", I would have some sympathy with that." (Committee member 8 , audio file 1 ) 
This comment directly impacted the final decision document, where the following line was added:

"[In terms of] necessary maternity care for which we show solidarity, we envision care with a medical purpose and not the image of the maternity care worker who serves beschuit met muisjes." (Discussion document 1.2)

This combination of quotes shows that different combinations play a role in the deliberations (cf. 17), and the decision-making process and the final decision benefit from linking these elements and contrasting these with other combinations in situ. It also highlights the expertise brought to bear in these processes.

Broadening the combination's scope appears to be not common in the published literature, where decisions hinge on explicated reasons and rarely concern other health care areas (cf. 21). However, the coverage decisions studied contain recommendations, and we pose this would fall squarely in this category (26). In the paracetamol-vitamin D case study, the primary rationale was that reimbursing these medicines would make them more expensive due to this prescription rule (see box 2 ). One of the appraisal committee members broadened the scope of the coverage decision, formulating it as if directly giving the Minister of Health advice on the prescription rule:

"You may make many more [medicines] available outside the pharmacy. Given the situation, this is our answer: if it has to be bought at the pharmacy, it has to be reimbursed. But we advise you to think carefully about the prescription rule because that creates a completely unequal ratio between those cheap medicines that are and those that are not available on prescription." (Committee member 6, audio file 2)

Giving the Minister advice on the prescription rule has little to do with demarcating the basic benefits basket; it falls outside the appraisal committee's remit. However, this type of recommendation provides an essential strengthening element of a combination. The scope of the decision is broadened by going beyond the coverage decision. Specifically, the direction the combination is broadened in through such recommendations remains at the committee's discretion. Sometimes they formulate advice to the Minister, sometimes to other stakeholders. In this way, the committee not only specifies what a good basic benefits basket is but also what good care entails, thereby actively broadening its remit.

Black-boxing links is the final and most robust aspect of designing combinations. The example provided by Rip concerns the black-boxed link between smoking and cancer (21). Black-boxing links, even more than broadening the scope of the combination, may be considered unchartered territory. Coming from a strong history of providing elaborate reasonings, with as many (predetermined) elements and links between elements visualised as possible (e.g., 57, 58), we argue that the idea of black-boxing may seem counter-intuitive. However, cost-effectiveness in and of itself could be seen as black-boxed, linking many separate elements such as quality-adjusted life years, costs per treatment, and effectiveness, into a widespread coverage criterion (45). In this sense, the committee's deliberations (almost) always employ a link that has been black-boxed for a long time. Black-boxing is also visible to some extent in the appraisal 
committee's work we have studied. The paracetamol-vitamin D tablets case featured the rule of thumb 'cheaper than $€ 100$ per year means no coverage'; the individual responsibility for the 'bottom' (cheaper end) of the benefits basket is noted, informally, to apply to any medicine cheaper than $€ 100$ per year. This rule of thumb is black-boxed in the sense that it is not done to question it. We observed how one committee member did question this black-boxed link tentatively, only for another to answer:

"We don't want a discussion on what price is affordable (lit: how much money can come for own account)" (Committee member 5, audio file 1)

Black-boxing links thus happens (but is naturally not explicated), with some links so black-boxed they are difficult to prise open.

\section{Step 3: Testing combinations}

The third and final step is to test these different designed decision combinations. The fact that different combinations may exist, and that one needs to be chosen, has previously been described for a decision for a costly treatment, which gained a positive coverage status because one set of clustered argumentations together weighed more heavily than another set $(15,16)$. Callon et al. describe this process as a series of negotiations and compromises in the hybrid forum setting, which "unleashes" the learning process to be harnessed as part of the decision $(17,18)$. The confrontation between laypersons and those holding expertise is vital for enabling this learning process. In the paracetamol-vitamin D case, pharmacists, patient organisations, medical specialists, and a pharmaceutical company argued in favour of coverage. As committee member 5 summarised on behalf of these groups:

"It concerns largely vulnerable groups, chronically ill elderly patients, people who are regularly on the receiving end of budget cuts, have little money, often deal with the accumulation of costs (...) this is the most necessary care, and that should be covered per definition, as it is, erm, cost-effective care with which you can prevent (additional) costs that might occur later on, for example when these people do not take these medicines and get fractures, (which is) miserable for those people (but) also means additional costs." (Committee member 5, observations/audio file 2)

This potent alternative combination of vulnerable groups, arguing in favour of coverage, required an equally strong combination arguing against coverage. Committee member 4 achieves this by making more links to the former combination and then dismissing this combination by noting it as another's responsibility:

"Through the argument of not being able to afford [the tablets] it seems as if (...) there is some sort of poverty boundary where people through the calcium tablets will suddenly end up on the wrong side. But in those cases, (...) there is probably already more going on, with those people, already the government, all kinds of related measures, rent subsidies, benefits, are happening. And it won't [mean] those benefits agencies will give extra benefits because of this tablet, but there is a whole host of expenses, gas, light, and oh yes, the costs of this medicine, so there's much more to it. I think it is almost, how should I say it, 
almost a self-centred idea that we or the [collective health] insurance were going to make the difference between poverty and no poverty. So, I would argue to leave the poverty and the not being able to afford [things] to agencies that deal with these things, [because] it will not be influenced by that one-and-a-half calcium tablet (...). You can talk about those 100 euros, but it is always, low cost - just put it aside." (Committee member 4, audio file 2).

First, this is a notable remark as it narrows the committee's responsibility, counter to broadening it (see above). Second, this combination was quickly considered decisive; the committee responded primarily by noting that this problem indeed should not be solved through health insurance (Committee member 6, audio file 2) and the fact that "the whole system is inefficient" (Committee member 4, audio file 2). It was, however, a source of little discussion. The maternity care case resonates with this, as the alternative combination successfully placed it on the agenda, as described above. After having summarised the linked combination based on newspaper Trouw, committee member 8 continues:

[But] I think it's important to indicate something like: "Yes, but wait a minute, maternity care is about other matters, er, breastfeeding, detecting risky situations, etc., etc., for which it is completely just to be calling for solidarity"." (Committee member 8, audio file 1)

This comment was also the source of little subsequent discussion. It similarly shows how different decision combinations are tested against each other in healthcare coverage decisions' deliberative phase.

\section{Conclusion}

Making health care coverage decisions requires decision makers to be nimble and responsive in some respects and consistent in others. It requires constructing processes and resulting decisions as both rational and human (24); as a result, in our view, it need not mean consistent application of criteria (9). Therefore, the model this paper proposes for robust decision outcomes cannot be prescriptive, for the robustness of decisions is constructed just as rationality is. Much depends on concerned actors' ongoing work and how they may perceive a decision outcome's relative robustness. This paper takes a theoretical angle to describe how robustness may be achieved and illustrates and confronts this with two concrete decision processes. As such, it does yield avenues to explore towards more robust decisions. First, these may include more careful preparatory work in terms of contents (identification of potential elements from a wide variety of sources). Second, it indicates paying attention to the set-up of the hybrid forum-like setting, enabling everyone to contribute in a way that is sensitive to the power differences inherent to such decision-making processes. Third, further research may investigate the relationship between combination strength and how actors perceive the outcome's robustness.

In STS literature, "plural solutions" are tested (that is, repeatedly confronted) by specialists and laypersons together to create 'hybrid knowledge' $(18)$ or even 'socially robust knowledge' $(22,23)$. From the two cases studied, it becomes clear that the process, for the moment, may not conform to this image completely. Therefore, we need to establish empirically to what extent these practices resemble the hybrid forum ideal already and how we could make it more so. One crucial aspect that has been the subject of 
extensive discussion is opening the decision setting up further to laypersons in addition to the patients already present at (some) appraisal committee meetings (e.g., 59, 60). This opening is, however, not without its problems.

An oft-heard objection to opening up the decision is that it would imply a "tendency to lead to a "levelling of the epistemological playing field' and to a collapse of the concept of expertise" $(31,52,54)$. A second objection is that the public engagement may be no more than a legitimation exercise (61). On the other end of the spectrum, the third is that personal interests may hijack deliberations (25). In response, we would follow Rip and Callon et al. in considering personal interests un-extractable and even constructive to the decision process $(17,21)$. The risk of expertise collapsing is not very prominent here because in both decisions examined, 'science proper' was represented by the Institute employee, who had a distinct role in the proceedings, demarcating their expertise in non-verbal ways. Our data also highlight the appraisal committee's expertise $(25,62,63)$ as crucial in linking elements; a form of expertise not directly based on their respective areas of training and employment. Precisely then because of the distinct role these two types of expert play, the risk of public engagement turning into a legitimation exercise is less quickly dispelled than the other two identified problems. In our data, however, we saw that the establishment and testing of combinations did happen. It was not 'for show' in the sense that the committee already made the decision beforehand. This finding underlines the potential of encouraging engagement for the right reasons and in the right ways. It also shows that these meetings may indeed be a "forum for debating social desirability of innovations not generally deemed to be highly controversial" (14), even though consensus is "no guarantee that interests and concerns [have been] considered in the decision-making process" (64). One form this may take is through further steps to institutionalise and facilitate appeals procedures, which may also help to counteract these risks.

We need a complex, nuanced picture of how robust coverage decisions are constructed. The picture we have painted values the knowledge that certified experts may bring in selecting and linking the decision elements. It also highlights that other combinations, other potentially robust decisions, are available for every decision made. Though no guarantee that these outcomes may withstand pressure 'out there', this model shows how coverage decisions may benefit from the contribution of alternative elements and combinations in their outcomes. It provides a strong rationale for the careful organisation of the deliberative setting and appeals procedure in ways that are easily accessible. It also highlights that future research could explore the relationship between decision combination strength and robustness.

\section{Abbreviations}

HTA Health Technology Assessment

STS Science and Technology Studies

\section{Declarations}


Ethics approval and consent to participate

An ethical waiver, MEC-2017-539, has been granted for this research by the Medical Ethics Committee at Erasmus Medical Centre Rotterdam, the Netherlands. This waiver indicates that no formal ethical review has been deemed necessary, because the research contained no medical-scientific research question and the interviewees have not been subjected to a treatment or behavioural intervention.

Permission for the observations and access to the audio files has been granted by the secretary of the Advisory Committee Package (in Dutch: Adviescommissie Pakket) at the Dutch National Health Care Institute. Consent to participate has been granted by the interviewees through written consent to be interviewed.

Consent for publication

All interviewees signed a consent for publication form for a previous version of this paper.

Availability of data and materials

Under the research protocol as submitted to the Medical Ethics Committee at [information to be added], interview audio files and transcripts are kept confidential, and interviewees are anonymised in the manuscript. The datasets used and/or analysed during the current study are available from the corresponding author on reasonable request.

Competing interests

Not applicable.

Funding

[Organisation to be added], grant number [information to be added]. This funding body had no role in the design of the study, the collection, analysis, and interpretation of data, or in writing or approving the final manuscript.

Authors' contributions

All authors conceived the research idea together. [First author] conducted the fieldwork, analysed the data, and wrote and revised the manuscript, with all authors agreeing on the final text.

Authors' information

[To be added should the article be accepted for publication]

Acknowledgements

[To be added should the article be accepted for publication] 


\section{References}

1. May C. Mobilising modern facts: health technology assessment and the politics of evidence. Sociology of Health \& Illness. 2006;28(5):513-32.

2. Cerri KH, Knapp M, Fernandez J-L. Decision making by NICE: examining the influences of evidence, process and context. Health Economics, Policy and Law. 2014;9(2):119-41.

3. Vuorenkoski L, Toiviainen H, Hemminki E. Decision-making in priority setting for medicines-a review of empirical studies. Health Policy. 2008;86(1):1-9.

4. Cromwell I, Peacock SJ, Mitton C. 'Real-world'health care priority setting using explicit decision criteria: a systematic review of the literature. BMC health services research. 2015;15(1):164.

5. Kleinhout-Vliek T, de Bont A, Boysen M, Perleth M, van der Veen R, Zwaap J, et al. Around the Tables - Contextual Factors in Healthcare Coverage Decisions Across Western Europe. International Journal of Health Policy and Management. 2020:-.

6. Williams I, Brown H, Healy P. Contextual factors influencing cost and quality decisions in health and care: a structured evidence review and narrative synthesis. International journal of health policy and management. 2018;7(8):683.

7. Clement FM, Harris A, Li JJ, Yong K, Lee KM, Manns BJ. Using effectiveness and cost-effectiveness to make drug coverage decisions: a comparison of Britain, Australia, and Canada. Jama. 2009;302(13):1437-43.

8. Kanavos P, Nicod E, Van Den Aardweg S, Pomedli S. The impact of health technology assessments: an international comparison. 2010.

9. Rotteveel AH, Lambooij MS, van de Rijt JJ, van Exel J, Moons KG, de Wit GA. What influences the outcome of active disinvestment processes in healthcare? A qualitative interview study on five recent cases of active disinvestment. BMC health services research. 2021;21(1):1-12.

10. Jenkings $\mathrm{KN}$, Barber N. What constitutes evidence in hospital new drug decision making? Social science \& medicine. 2004;58(9):1757-66.

11. Light DW, Hughes D. Introduction: A sociological perspective on rationing: power, rhetoric and situated practices. Sociology of Health \& Illness. 2001;23(5):551-69.

12. Ham C, Glenn R. Reasonable rationing: McGraw-Hill Education (UK); 2003.

13. Hughes D, Doheny S. Constructing 'exceptionality': a neglected aspect of NHS rationing. Sociology of Health \& Illness. 2019;41(8):1600-17.

14. Lehoux P, Denis JL, Rock M, Hivon M, Tailliez S. How medical specialists appraise three controversial health innovations: scientific, clinical and social arguments. Sociology of Health \& Illness. 2010;32(1):123-39.

15. Martin D, Pater J, Singer P. Priority-setting decisions for new cancer drugs: a qualitative case study. The Lancet. 2001;358(9294):1676-81.

16. Singer PA, Martin D, Giacomini Bhatia MV, Purdy L. Priority setting for new technologies in medicine: qualitative case study. BMJ. 2000;321(7272):1316-8. 
17. Callon M, Lascoumes P, Barthe Y. Acting in an uncertain world: An essay on technical democracy (G. Burchell, Trans.). Cambridge, MA: MIT Press; 2009.

18. Moreira T. Health care rationing in an age of uncertainty: a conceptual model. Social Science \& Medicine. 2011;72(8):1333-41.

19. Moreira T. The transformation of contemporary health care: the market, the laboratory, and the forum. USA: Routledge; 2013.

20. Rip A. Experts in public arenas. Regulating industrial risks: Science, hazards and public protection. 1985:94-110.

21. Rip A. Controversies as Informal Technology A ssessment. Knowledge. 1986;8(2):349-71.

22. Rip A. Social robustness and the mode 2 diagnosis. Science, Technology \& Innovation Studies. 2010;6(1).

23. Nowotny H. Democratising expertise and socially robust knowledge. Science and public policy. 2003;30(3):151-6.

24. Russell J, Greenhalgh T. Being 'rational'and being 'human': How National Health Service rationing decisions are constructed as rational by resource allocation panels. Health:. 2014;18(5):441-57.

25. Calnan M, Hashem F, Brown P. Still elegantly muddling through? NICE and uncertainty in decision making about the rationing of expensive medicines in England. International Journal of Health Services. 2017;47(3):571-94.

26. Kleinhout-Vliek T, De Bont A, Boer B. Necessity under construction - societal weighing rationality in the appraisal of health care technologies. Journal of health economics, policy, and law. 2020.

27. Russell J, Swinglehurst D, Greenhalgh T. 'Cosmetic boob jobs' or evidence-based breast surgery: an interpretive policy analysis of the rationing of 'low value'treatments in the English National Health Service. BMC health services research. 2014;14(1):413.

28. Russell J. The rationality of rationing: a rhetorical policy analysis of deliberations about resource allocation in the NHS: University of Oxford; 2017.

29. Jasanoff S. Genealogies of STS. Social Studies of Science. 2012;42(3):435-41.

30. Martin B, Richards E. Scientific knowledge, controversy, and public decision-making. Handbook of science and technology studies. 1995;506:26.

31. Epstein S. Misguided boundary work in studies of expertise: Time to return to the evidence. Critical policy studies. 2011;5(3):323-8.

32. Nowotny H, Scott PB, Gibbons MT. Re-thinking science: Knowledge and the public in an age of uncertainty. Cambridge, UK: John Wiley \& Sons; 2013.

33. Lehoux P. The problem of health technology. USA: Routledge; 2014.

34. Makady A, ten Ham R, de Boer A, Hillege H, Klungel O, Goettsch W. Policies for use of real-world data in health technology assessment (HTA): a comparative study of six HTA agencies. Value in Health. 2017;20(4):520-32. 
35. Ragin CC. Turning the tables: How case-oriented research challenges. Rethinking social inquiry: Diverse tools, shared standards. 2004;123.

36. Creswell JW, Poth CN. Qualitative inquiry and research design: Choosing among five approaches. USA: Sage publications; 2017.

37. Dussauge I, Helgesson C-F, Lee F. Value Practices in the Life Sciences and Medicine: Oxford University Press, USA; 2015.

38. Lamont M. Toward a Comparative Sociology of Valuation and Evaluation. Annual Review of Sociology. 2012;38(1):201-21.

39. Kleinhout-Vliek T. Weaving Necessity: Contextualisation Practices for Achieving Robust Health Care Coverage Decisions. Rotterdam: Erasmus University Rotterdam; 2020.

40. Van der Aa E. Zware paracetamol en vitaminen wellicht uit pakket. Algemeen Dagblad. 2016.

41. Unknown. Zware paracetamol mogelijk uit basispakket: klap voor honderdduizenden patiënten. RTL nieuws. 2016.

42. Frey JH, Fontana A. The group interview in social research. The Social Science Journal. 1991;28(2):175-87.

43. King N, Horrocks C, Brooks J. Interviews in qualitative research. UK: SAGE Publications Limited; 2018.

44. Zorginstituut Nederland. Pakketbeheer in de praktijk deel 3. Diemen; 2013.

45. Franken M, le Polain M, Cleemput I, Koopmanschap M. Similarities and differences between five European drug reimbursement systems. International Journal of Technology Assessment in Health Care. 2012;28(4):349-57.

46. Patera N, Wild C. Assessment - APPRAISAL - Decision. LBI-HTA Decision Support Document Nr.: 72. Wien: Ludwig Boltzmann Institut für Health Technology Assessment; 2014.

47. Walley T. Health technology assessment in England: assessment and appraisal. Medical Journal of Australia. 2007;187(5):283.

48. Zorginstituut Nederland. Pakketadvies in de praktijk: wikken en wegen voor een rechtvaardig pakket. Diemen; 2017.

49. Zorginstituut Nederland. Reglement Adviescommissie Pakket. https://www.zorginstituutnederland.nl/over-ons/publicaties/besluit/2016/12/05/reglementadviescommissie-pakket-zorginstituut-nederland (accessed 11 February 2020); 2016.

50. Cerri KH, Knapp M, Fernandez J-L. Public funding of pharmaceuticals in the Netherlands: investigating the effect of evidence, process and context on CVZ decision-making. The European Journal of Health Economics. 2014;15(7):681-95.

51. Callon M. The role of lay people in the production and dissemination of scientific knowledge. Science, Technology and Society. 1999;4(1):81-94.

52. Collins $H$, Weinel M, Evans R. The politics and policy of the Third Wave: new technologies and society. Critical policy studies. 2010;4(2):185-201. 
53. Rip A. Constructing expertise: In a third wave of science studies? Social studies of science. 2003;33(3):419-34.

54. Fischer F. The 'policy turn'in the Third Wave: return to the fact-value dichotomy? Critical policy studies. 2011;5(3):311-6.

55. Jasanoff S. Breaking the waves in science studies: comment on HM Collins and Robert Evans,The third wave of science studies'. Social studies of science. 2003;33(3):389-400.

56. Kleinhout-Vliek T, de Bont A, Boer B. The bare necessities? A realist review of necessity argumentations used in health care coverage decisions. Health Policy. 2017;121(7):731-44.

57. Bærøe K, Baltussen R. Legitimate Healthcare Limit Setting in a Real-World Setting: Integrating Accountability for Reasonableness and Multi-Criteria Decision Analysis. Public Health Ethics. 2014;7(2):98-111.

58. Guindo LA, Wagner M, Baltussen R, Rindress D, van Til J, Kind P, et al. From efficacy to equity: Literature review of decision criteria for resource allocation and healthcare decisionmaking. Cost Effectiveness and Resource Allocation. 2012;10(1):9.

59. Abrishami P, Boer A, Horstman K. Value in co-creation: Subjecting innovative in-hospital technologies to multi-stakeholder appraisal. Public Value of Medical Innovations. 2017;1:97.

60. Baltussen R, Jansen MP, Mikkelsen E, Tromp N, Hontelez J, Bijlmakers L, et al. Priority Setting for Universal Health Coverage: We Need Evidence-Informed Deliberative Processes, Not Just More Evidence on Cost-Effectiveness. International Journal of Health Policy and Management. 2016;5(11):615-8.

61. Munk AK, Meunier A, Venturini T. Data sprints: A collaborative format in digital controversy mapping: Princeton University Press Princeton, NJ; 2016.

62. Hughes D, Light D. Rationing: constructed realities and professional practices. Oxford, UK: WileyBlackwell; 2002.

63. 63.

64. Jamal T, Getz D. Community roundtables for tourism-related conflicts: The dialectics of consensus and process structures. Journal of Sustainable Tourism. 1999;7(3-4):290-313. 